\title{
Análise Espacial da Distribuição de Sensores para Detecção de Incêndios Florestais no Parque Estadual da Serra do Rola Moça
}

\author{
Sílvia Albuquerque ${ }^{1}$, Fábio Silva ${ }^{1}$, Diógenes Oliveira ${ }^{1}$ \\ ${ }^{1}$ Departamento de Computação do CEFET-MG \\ Av. Amazonas 7675, Nova Gameleira, Belo Horizonte, MG, Brasil \\ \{silviacalmon, fabio.rocha\}@cefetmg.br \\ diogenesvazmelo@gmail.com.br
}

\begin{abstract}
This article presents a possible sensors distribution methodology for wildfire detection in a state park, Parque Estadual da Serra do Rola Moça (PESRM), in order to contribute to the development of a prototype Internet of Things (IoT) system. The data used in this research was made available by the Instituto Nacional de Pesquisas Espaciais (INPE) through a wildfire monitoring program, and it can be downloaded on the INPE's website. The proposed location for the sensors was set by the application of a clustering algorithm ( $K$ means) over a total of five groups (quantity defined by the elbow method) in the data of wildfires registered between the years 1999 and 2020. To improve the model was suggested to provide sensors also at the highest points of the terrain.
\end{abstract}

Resumo. Este artigo apresenta uma possível metodologia de distribuição para sensores de detecção de incêndio no Parque Estadual da Serra do Rola Moça (PESRM), a fim de contribuir com o desenvolvimento de um protótipo de sistema de Internet das Coisas para tais eventos. O estudo teve como ponto de partida a localização dos focos de incêndio registrados entre os anos de 1999 e 2020 no PESRM, e prosseguiu com a aplicação de um algoritmo de agrupamento ( $K$ means) para cinco grupos, quantidade definida por meio do método do cotovelo. A conclusão foi por estabelecer a localização dos sensores nos centróides dos grupos encontrados, reforçando o sistema ao acrescentar sensores também nos pontos mais elevados do terreno. 


\section{Caracterização do Problema}

Segundo o Manual para Formação de Brigadista de Prevenção e Combate aos Incêndios Florestais [Lemos et al. 2010], incêndio florestal é todo fogo sem controle que incide sobre qualquer forma de vegetação, podendo tanto ser provocado pelo homem ou por causas naturais. [Castro et al. 2003] identificam três fatores que influenciam no comportamento dos incêndios florestais: o tipo de combustível, tipo de relevo e as condições meteorológicas.

O combustível é fundamental para o surgimento e propagação do fogo [Silva 2016], pois a combustão não é possível se não houver material para se queimar. Em meio à vegetação, existem combustíveis florestais, caracterizados por todos os materiais vegetais que se encontram na floresta, provenientes de plantas vivas ou mortas. A diferença entre plantas vivas e mortas, enquanto combustível, é a quantidade de água: nas primeiras, há elevada quantidade de água, já, nas segundas, o teor de água é muito mais baixo, podendo variar com a umidade do ar [Castro et al. 2003].

A maior ou menor inclinação de uma encosta também tem influência determinante na propagação dos incêndios: maiores declividades acentuam o efeito das colunas de convecção de ar, que aquecem a vegetação acima do incêndio e aumentam a velocidade de propagação em direção às partes mais elevadas do terreno [Castro et al. 2003]. Portanto, numa encosta, o incêndio propaga-se muito mais rapidamente no sentido ascendente que no descendente.

A rapidez e a eficiência na detecção e monitoramento dos incêndios florestais são imprescindíveis para o controle do fogo e para a redução de custos no combate e de danos. Logo, os métodos de detecção e monitoramento de incêndios florestais são essenciais para o controle e o dimensionamento dos efeitos causados pelas chamas sobre o meio ambiente [Batista 2004].

Segundo [Batista 2004], podem ser utilizadas diversas técnicas para a detecção de incêndios florestais, tais como vigilância terrestre por postos de vigilância e torres de observação, patrulhamentos terrestres ou aéreos e por imagens de satélites. Alkhatib, na publicação de seus estudos sobre detecção de fogo em florestas, determina que

se comparada às soluções citadas, sistemas baseados em sensores e Internet das Coisas (Internet of Things - IoT) possuem uma das melhores relações custo-benefício [...]. Esses sistemas possuem um menor tempo entre o início do incêndio e o alerta aos responsáveis, além de uma maior manutenibilidade. Alkhatib 2014, tradução nossa

Esse artigo se propõe a dar continuidade à pesquisa sobre um sistema de internet das coisas para detecção de incêndios florestais realizada por [Albuquerque et al. 2020] ao definir o posicionamento e quantificação de sensores na área de estudo.

\section{2. Área de Estudo}

A área de estudo em questão se trata do Parque Estadual da Serra do Rola Moça (PESRM), que possui importância estratégica para a região metropolitana de Belo Horizonte. Possui 3.941,09 hectares e faz limite com os municípios de Belo Horizonte, Brumadinho, Ibirité e Nova Lima [Drumond 2018]. A Figura 1] é uma representação que ilustra, em vermelho, a linha de perímetro do parque e seu entorno. 
De acordo com [Peixoto 2004], o clima do PESRM é classificado dentro da faixa de transição térmica entre tropical e subtropical, com intensidade de radiação solar elevada. A altitude média de 1.300 metros ameniza as altas temperaturas. O regime de chuva representa bem as características da região sudeste do Brasil, com verões chuvosos e invernos secos.

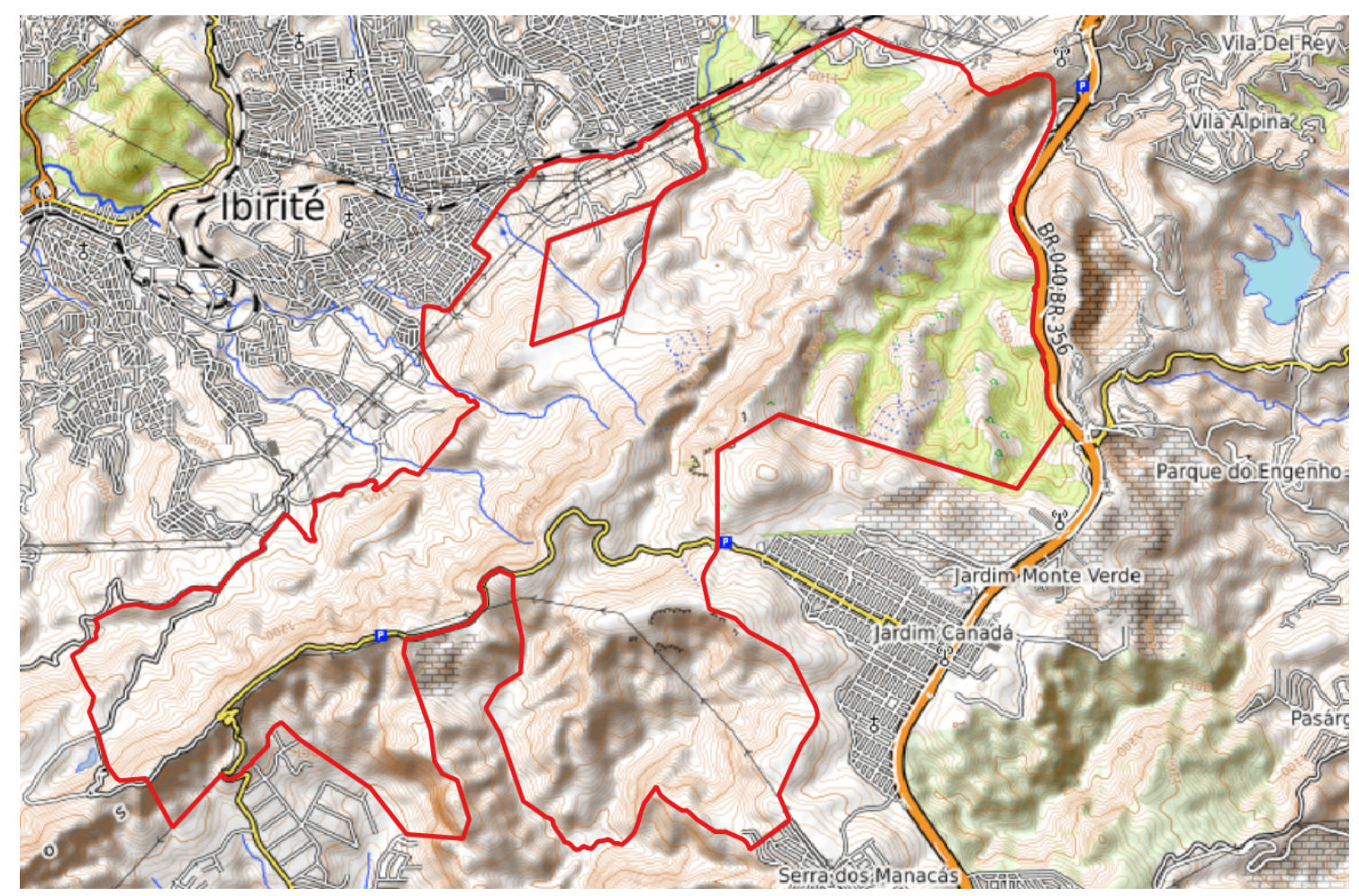

Figura 1. Limites do Parque Estadual da Serra do Rola Moça.

O Corpo de Bombeiros Militar de Minas Gerais possui um pelotão de combate a incêndios florestais no interior do PESRM. Tal pelotão possui a atribuição de realizar atividades preventivas e de combate às queimadas no interior e nas proximidades do parque.

\section{Objetivo}

O objetivo dessa pesquisa é definir espacialmente a melhor disposição para sensores que possam indicar a ocorrência, em tempo real, de um incêndio na área de estudo. Esses sensores, em conjunto com dispositivos de comunicação e uma plataforma Web de monitoramento, fazem parte do desenvolvimento de um sistema protótipo de Internet das Coisas [Albuquerque et al. 2020]. Espera-se utilizar dados de monitoramento via satélite para definir a posição dos sensores, de forma a considerar o histórico de focos de queimadas na área de estudo, pois, dessa forma, aglutina-se a influência exercida por questões de infraestrutura, climatológicas, topográficas e antrópicas no decorrer dos anos. Com esse trabalho, almeja-se contribuir com o Corpo de Bombeiros Militar de Minas Gerais e brigadistas ao aumentar a eficiência no combate a incêndios.

\section{Metodologia}

A conclusão obtida por [Albuquerque et al. 2020] relativa à atuação dos sensores revelou que estes só detectam o fogo em suas proximidades imediatas, ou seja, não 
possuem um raio de atuação. [Argany et al. 2011] propôs uma abordagem que se valia de uma análise espacial com diagrama Voronoi e triangulação de Delaunay para otimizar uma rede de sensores wireless, entretanto, a característica de atuação dos sensores avalidados por [Albuquerque et al. 2020] implicou na adoção de uma metodologia distinta.

Para esse estudo, foram utilizados dados, de domínio público, dos focos de queimadas ocorridos no PESRM entre o primeiro dia de janeiro de 1999 até o último dia de dezembro de 2020. Tais dados são fornecidos pelo Instituto Nacional de Pesquisas Espaciais (INPE), referentes ao [Programa Queimadas Monitoramento por Satélites ] $]$ e podem ser obtidos no site do Instituto, no ícone "bancos de dados de queimadas".

Os dados do site foram exportados em arquivos de extensão .csv e, em seguida, exploraram-se informações relevantes sobre focos de queimadas presentes nesses arquivos: data e hora, dias sem chuva, posição em latitude e longitude, dentre outros. Para esse estudo, foram selecionadas as latitudes e longitudes, sem distinção de outros fatores, a fim de mapear as áreas nas quais, históricamente, houveram mais registros de incêndios.

Assim, gerou-se o gráfico de dispersão da Figura 2 , no qual constam, no eixo horizontal, a longitude, no eixo vertical, a latitude, e, em azul, os focos de incêndio registrados pelo INPE entre 1999 e 2020.

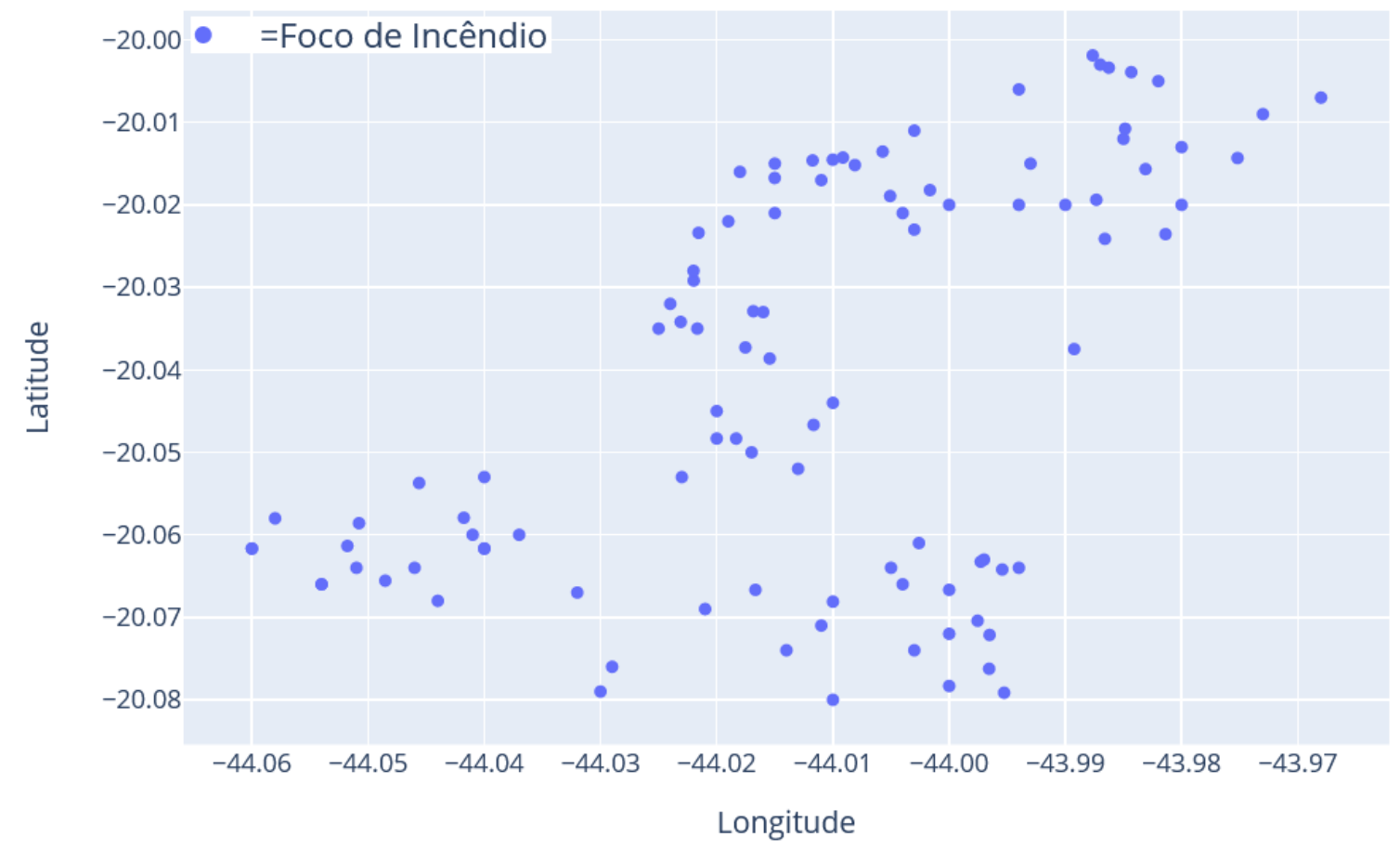

Figura 2. Dispersão da localização dos focos de incêndio registrados

Para definir a posição dos sensores foi adotado o algoritmo de agrupamento KMeans, que identifica centróides para $k$ grupos de dados.

Esse método de análise é um método de agrupamento não-hierárquico por repartição, que consiste num procedimento em que, dado um número de clusters previamente determinado, calcula-se pontos que representam

\footnotetext{
${ }^{1}$ Disponível em: http://queimadas.dgi.inpe.br/queimadas/bdqueimadas/. Acesso em 15 mar 2021.
} 
os "centros" desses clusters, espalhados homogeneamente no conjunto de respostas obtidas [...] e movidos, heuristicamente, até grupos preestabelecidos, e a melhor partição dos ' $n$ ' casos será aquela que otimize o critério escolhido. [Guidini et al. 2008]

Os grupos, representando a quantidade de sensores a serem utilizados, foram inferidos com o auxílio do método do cotovelo. Tal método consiste em calcular a inércia total da melhor solução para diversas quantidades de grupos, sendo esperado que a inércia para apenas um grupo seja a mais elevada, e decaia conforme a quantidade de grupos aumenta. Ao final, é escolhido o número de grupos que mais de distancia da reta formada entre o primeiro e o último valor testado.

No gráfico da Figura 3, são apresentados os testes dos valores de inércia para até vinte grupos. Quanto mais grupos, mais o valor da inércia se aproxima de zero. Nessa situação, o valor ótimo retornado pelo método do cotovelo foi de cinco grupos (clusters).



Figura 3. Inércia por quantidade de sensores.

\section{Resultados}

Fornecendo ao algoritmo K-Means o valor de $k$ igual a cinco, os resultados obtidos para as posições dos centróides, ou seja, dos sensores, estão descritos na Tabela 1 .

Tabela 1. Resultado do algoritmo K-Means

\begin{tabular}{|c|c|c|}
\hline & Latitude & Longitude \\
\hline 1 & -20.063087 & -44.045450 \\
\hline 2 & -20.017521 & -44.009779 \\
\hline 3 & -20.069676 & -44.003185 \\
\hline 4 & -20.013545 & -43.984378 \\
\hline 5 & -20.040139 & -44.018699 \\
\hline
\end{tabular}


A fim de ilustrar o resultado, a Figura 4 repete a dispersão dos focos de incêndio apresentada na Figura 2, mas, desta vez, são adicionados também os cinco pontos da Tabela 1, que caracterizam a posição dos sensores. Observam-se os pontos azuis, representando focos de incêndio e, os pontos vermelhos, a localização sugerida dos sensores. Apesar de alguns focos de incêndio mais distantes, os sensores estariam posicionados em meio aos locais de maior incidência.

A Figura 5 adiciona, em relação à ilustração da Figura 1, a localização sugerida dos sensores, representados por círculos vermelhos, no PESRM.

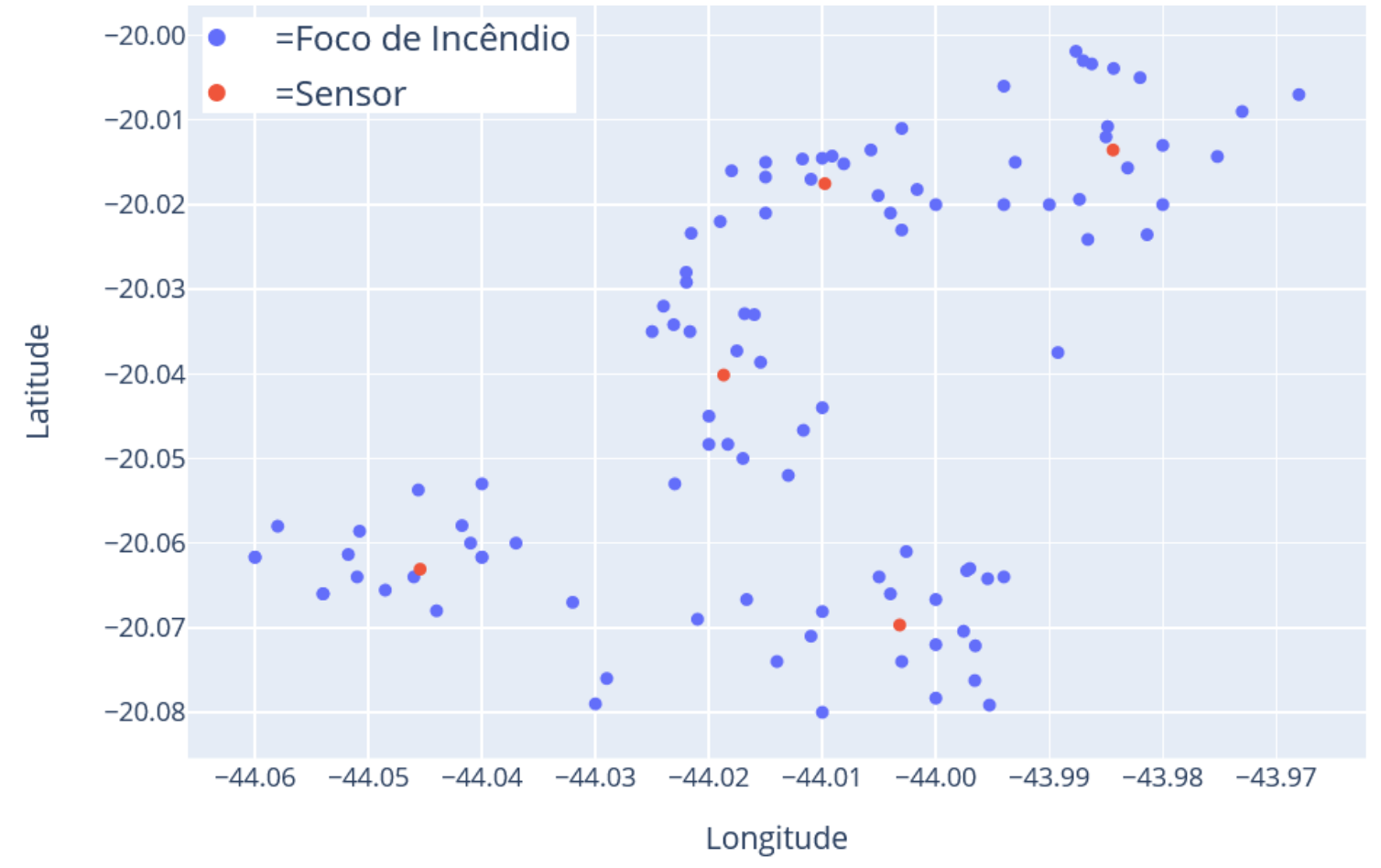

Figura 4. Dispersão da localização dos sensores e focos de incêndio.

É necessário, ainda, validar o modelo através de testes em campo. Devido a fatores como a velocidade de propagação do fogo, o tempo de resposta da brigada de incêndio e as condições climáticas e da vegetação, o proposto pode se revelar insuficiente ou demandar ajustes.

\section{Conclusão}

Espera-se que o uso dos sensores de detecção auxilie o trabalho do Corpo de Bombeiros Militar de Minas Gerais e contribua para a mitigação dos danos ambientais causados por incêndios florestais. Entretanto, esse estudo se concentrou apenas em definir a quantidade mínima e localização dos sensores, portanto, é necessário esforço no sentido de desenvolver um protótipo com o intuito de validar o sistema.

Deve-se considerar também que o número de sensores indicados refere-se a uma quantidade mínima, e não garante que qualquer foco de incêndio será detectado. A localização indicada dos sensores tem como base os locais de maior incidência nos últimos anos, portanto, focos localizados a uma distância maior podem não ser detectados. 


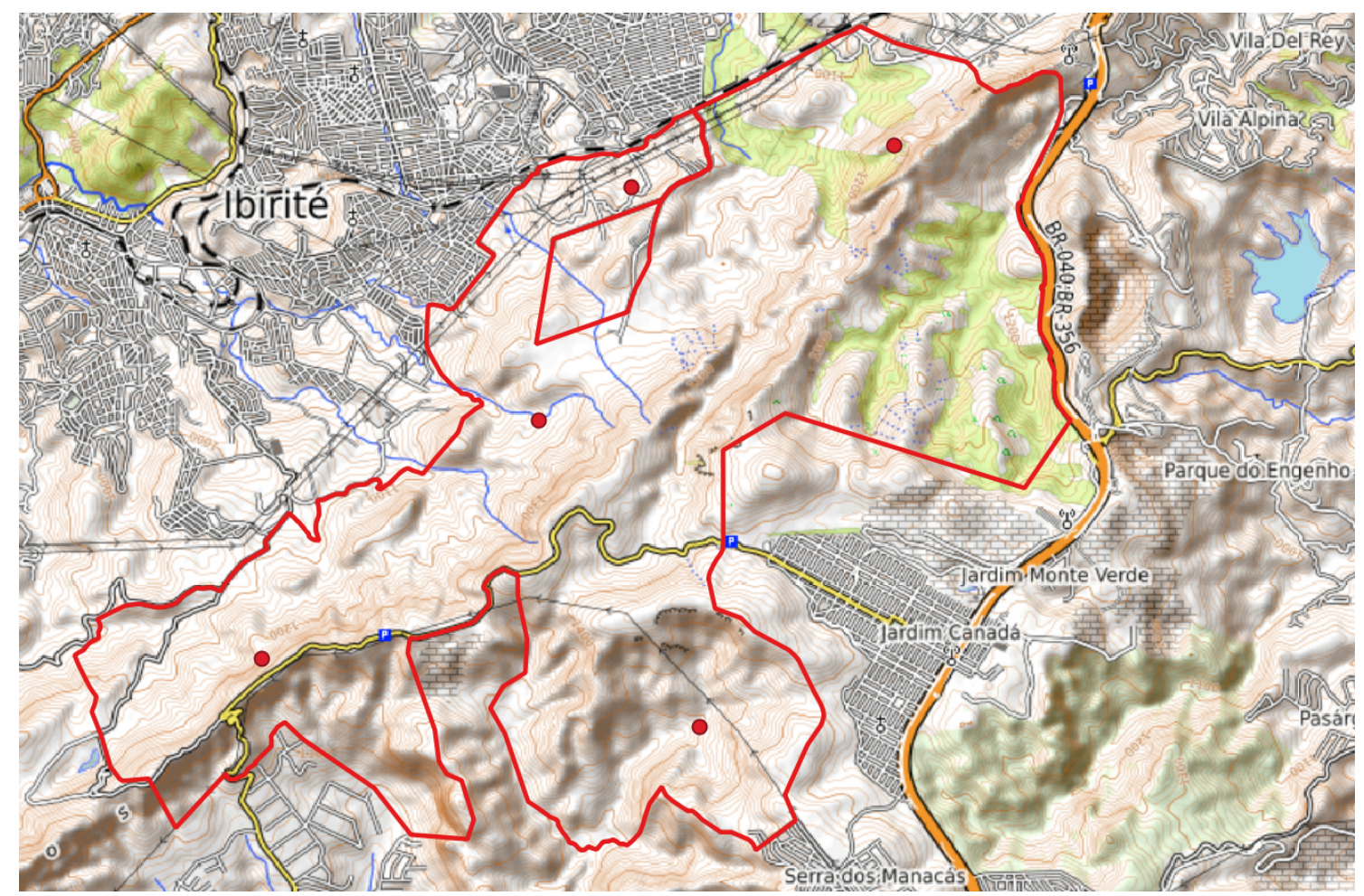

Figura 5. Localização dos sensores (círculos vermelhos) no PESRM.

Um modelo estruturado sob dados passados não pondera que mudanças climáticas, ou de características do entorno, são capazes de aumentar a incidência de focos de incêndio em uma região do Parque, até então, historicamente com poucos registros. Dessa forma, sugere-se complementar o modelo adicionando sensores nas porções mais elevadas do terreno, dada a maior velocidade de propagação do fogo no sentido ascendente em encostas, a fim de prover mais assertividade ao sistema.

Outro ponto a salientar refere-se ao custo de implantação e manutenção do sistema. É imperativo que o custo unitário dos sensores, bem com a quantidade destes, se mantenham baixos, pois, dessa forma, será viável aplicar o modelo de distribuição apresentado neste trabalho.

Ademais, a literatura, em especial a lusófona, sobre o tema de IoT para detecção de incêndios florestais não é vasta. Nesse sentido, a intenção é que essa pesquisa contribua e estimule a busca de avanços tecnológicos sobre esse tema, sobretudo devido à sua importância para a segurança ambiental.

\section{Referências}

Albuquerque, S., Fonseca, D., Lima, R. L., Milanés, A., Rocha, I., Santos, A. M., Silva, G., and Vieira, F. (2020). Sistema de internet das coisas para detecção de incêndios florestais. In Anais do XI Workshop de Computação Aplicada à Gestão do Meio Ambiente e Recursos Naturais, pages 141-150, Porto Alegre, RS, Brasil. SBC.

Alkhatib, A. A. (2014). A review on forest fire detection techniques. International Journal of Distributed Sensor Networks, 10(3):597368. 
Argany, M., Mostafavi, M. A., Karimipour, F., and Gagné, C. (2011). A gis based wireless sensor network coverage estimation and optimization: A voronoi approach. In Transactions on Computational Science XIV, volume 6970, pages 151-172, Springer, Berlin, Heidelberg. Lecture Notes in Computer Science.

Batista, A. C. (2004). Detecção de incêndios florestais por satélites. Revista FLORESTA, $34: 237-241$.

Castro, C. F., Serra, G., Parola, J., Reis, J., Lourenço, L., and Correia, S. (2003). Combate a incêndios florestais. Escola Nacional de Bombeiros.

Drumond, J. (2018). Parque Estadual do Rola Moça entra para o Hall da Fama do TripAdvisor. Disponível em: http://www.ief.mg.gov.br/noticias/1/2511-parque-estadualdo-rola-moca-entra-para-o-hall-da-fama-do-tripadvisor. Acesso em 30 mai 2021.

Guidini, M. B., Nascimento, A. M., Bone, R. B., and Alves, T. W. (2008). Aplicação do kmeans cluster para classificar estilos gerenciais. Revista Contemporânea de Economia e Gestão, 6:25-34.

Lemos, A. F., Junior, E. E., Bezerra, F. W. B., Zaluar, H. L. T., Dau, J. Z. R., Faria, L. P., Motta, M. S., and Willmersdorf, O. R. (2010). Manual para Formação de Brigadista de Prevenção e Combate aos Incêndios Florestais. Disponível em: https://www.icmbio.gov.br/portal/images/stories/servicos/sejaumbrigadista.pdf. Acesso em 30 mai 2021.

Peixoto, A. C. (2004). Diversidade na adversidade: gestão de unidade de conservação em área urbana - o Parque Estadual da Serra do Rola Moça. Dissertação (Pós-graduada em Ciências Sociais), PUC Minas (Pontifícia Universidade Católica de Minas Gerais), Belo Horizonte, Brazil.

Programa Queimadas Monitoramento por Satélites. Banco de Dados de Queimadas. Disponível em: http://queimadas.dgi.inpe.br/queimadas/bdqueimadas/. Acesso em 15 mar 2021.

Silva, B. H. (2016). Análise espacial dos focos de queimadas no Parque Estadual da Serra do Rola Moça, MG. Monografia (Bacharel em Engenharia Ambiental e Sanitária), CEFET-MG (Centro Federal de Educação Tecnológica de Minas Gerais), Belo Horizonte, Brazil. 